\title{
OVERVIEW OF THE DOE HYDROGEN SAFETY, CODES AND STANDARDS PROGRAM, PART 3: ADVANCES IN RESEARCH AND DEVELOPMENT TO ENHANCE THE SCIENTIFIC BASIS FOR HYDROGEN REGULATIONS, CODES AND STANDARDS
}

\author{
San Marchi, C. ${ }^{1}$, Hecht, E.S. ${ }^{1}$, Ekoto, I.W. ${ }^{1}$, Groth, K.M. ${ }^{2}$, LaFleur, C. ${ }^{2}$, Somerday, B.P. ${ }^{1}$, \\ Mukundan, R. ${ }^{3}$ and Rockward, T. ${ }^{3}$, Keller, J. ${ }^{4}$, James, C.W. ${ }^{5}$ \\ ${ }^{1}$ corresponding author: cwsanma@sandia.gov, Sandia National Laboratories, Livermore CA \\ 94550, USA \\ ${ }^{2}$ Sandia National Laboratories, Albuquerque NM 87185, USA \\ ${ }^{3}$ Los Alamos National Laboratory, Los Alamos NM 87545, USA \\ ${ }^{4}$ Zero Carbon Energy Solutions, Inc, Oakland CA 94603, USA \\ ${ }^{5}$ Fuel Cell Technologies Office, Department of Energy, Washington DC 20560, USA
}

\begin{abstract}
Hydrogen fuels are being deployed around the world as an alternative to traditional petrol and battery technologies. As with all fuels, regulations, codes and standards are a necessary component of the safe deployment of hydrogen technologies. There has been a focused effort in the international hydrogen community to develop codes and standards based on strong scientific principles to accommodate the relatively rapid deployment of hydrogen-energy systems. The need for science-based codes and standards has revealed the need to advance our scientific understanding of hydrogen in engineering environments. This brief review describes research and development activities with emphasis on scientific advances that have aided the advancement of hydrogen regulations, codes and standards for hydrogen technologies in four key areas: (1) the physics of high-pressure hydrogen releases (called hydrogen behavior); (2) quantitative risk assessment; (3) hydrogen compatibility of materials; and (4) hydrogen fuel quality.
\end{abstract}

\section{INTRODUCTION}

Hydrogen fuels are being deployed around the world as an alternative to traditional petrol and battery technologies in a wide range of applications. Hydrogen fuel cell replacements for battery packs on lift trucks for indoor warehouses, for example, is rapidly expanding [1,2,3]. Hydrogen backup power units have been deployed for numerous applications, especially cell-phone towers. Many innovative products have been developed to exploit the clean, quiet efficiency of fuel systems, including mobile light towers [4], maritime power units [5], and many others [6,7]. The largest investments for hydrogen have been for fuel-cell electric vehicles (FCEVs) for light-duty fleet vehicles (such as busses) and consumer automobiles. These applications require codes and standards to ensure safety of these systems and the public. Additionally, codes and standards are needed for hydrogen production, hydrogen transportation and hydrogen dispensing to support the use of hydrogen as an energy carrier.

In general, new technologies grow slowly over time with regulations, codes and standards (RCS) evolving via engineering experience and expert opinion. Often the development of new RCS is based on experience from a related field and related engineering principles. For hydrogen fuel systems in the consumer market, however, there is no clear analog from which to draw. Hydrogen exhibits numerous unique characteristics that prevent extrapolation from other fuels, such as the need for storage at high pressure (>700 bar) or at extremely low temperature $(20 \mathrm{~K})$ to accommodate high volumetric efficiency. Additionally, hydrogen has unique thermodynamic properties (i.e., flammability), embrittles most structural metals, is difficult to detect, and requires high-purity for fuel-cell applications. For these reasons, comprehensive scientific understanding of the behavior of hydrogen is 
critical to the development of robust safety strategies in consumer markets as well as a meaningful scientific-basis for RCS.

In this brief overview, we describe scientific and engineering advances that have enabled the development of codes and standards for hydrogen technologies. This report focuses on four key technology areas where science has been impactful to the hydrogen regulations, codes and standards communities: (1) the physics of high-pressure hydrogen releases (called here hydrogen behavior); (2) quantitative risk assessment (QRA); (3) hydrogen compatibility of materials; and (4) hydrogen fuel quality.

\section{HYDROGEN BEHAVIOR}

\subsection{Behavior Models}

An understanding of hydrogen physics is essential to provide a scientific basis for the development of regulations, codes and standards. Regulations, codes and standards are written and employed to limit the occurrence of hazards and harm, and therefore require knowledge of the evolution of hazards (e.g., the dispersal characteristics of hydrogen from a leak), and the consequences from harm-causing events (e.g., the magnitude of heat-flux associated with a defined hydrogen flame). Behavior models enable quantification of the hazard and the associated consequences, which can be used to evaluate the risk associated with a particular scenario. Computational fluid dynamics (CFD) is one method to evaluate hazards from the release of hydrogen, however, CFD requires expertise in fluid dynamics and substantial computing resources for relevant problems. To enable real-time calculations of hazards and consequences, as well as flexibility in defining boundary conditions of the scenarios, the hydrogen behavior work described here focuses on developing and validating reduced order models that can run quickly on a standard PC. These physics-based models can then be integrated with probabilistic models to quantitatively evaluate risk for a large number of accident scenarios, as described in section 3. In this section, we provide a description of several hydrogen behavior models that are currently being (or have recently been) used to inform code development activities and are being integrated into risk tools.

This work focuses on the codes and standards that guide the siting of hydrogen fueling stations. Current fuel cell vehicles store hydrogen at pressures of 35 or $70 \mathrm{MPa}$, and therefore our models must be valid for high-pressure systems. While the ideal gas equation of state is valid for hydrogen at low pressures, significant errors can occur at high pressure. Figure 1 shows the error in the density for two equations of state relative to the standard reference density (real-gas equation of state) [8,9], where a positive error means that the calculated density is higher than the standard reference density. The right-panel of Figure 1shows the error for the Abel-Nobel equation of state, where the state variables are related via the equation

$P\left(\frac{1}{\rho}-b\right)=\frac{R T}{W}$,

where $P$ is the pressure, $\rho$ is the density, $b$ is the co-volume constant $\left(7.691 \times 10^{-3} \mathrm{~m}^{3} / \mathrm{kg}\right.$ for hydrogen), $R$ is the ideal gas constant, and $W$ is the molecular weight (note that this reduces to the ideal gas equation of state when $b$ is 0 ). It is quite clear from this figure that the Abel-Nobel equation of state is much more accurate at pressures up to $200 \mathrm{MPa}$, while the ideal gas equation of state can only be used to around $5 \mathrm{MPa}$ without incurring significant errors. In much of our work, the AbelNobel equation of state is used to relate the pressure, temperature and density.

\subsubsection{Plume/jet model}

An unignited hydrogen release will form a plume, or a jet, depending on the momentum in the release. Our approach to model this phenomenon is to conserve mass, momentum, species, and energy in one-dimension along the jet length [10,11]. By assuming that the radial velocity, density, and mass fraction profiles are Gaussian, which is confirmed by experiments [12], a first order system of ODE's are obtained from the conservation equations [13]. Since the model is only one-dimensional along the 
streamline coordinate, correlations are used to calculate the amount of air entrainment along the jet length due to buoyancy and momentum. This system of equations is integrated along the length of the plume/jet, using a fourth order Runga-Kutta scheme implemented in the SciPy library of Python [14]. This integral model is valid in the momentum-dominated, buoyancy-dominated, and transition regions of plume/jet. The model can be used to predict the flammable extents of the plume/jet and inform standoff distances for hazardous equipment [15]. The challenge in implementing this model is specifying the boundary conditions at the start of the plume/jet for most release scenarios.
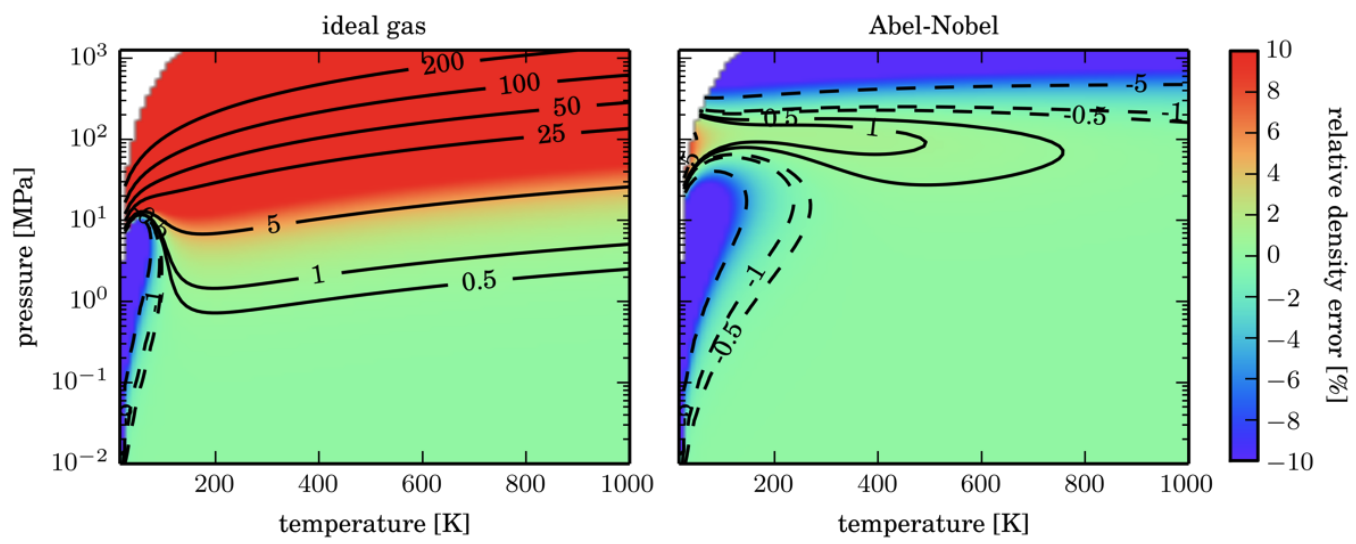

Figure 1. Error in calculated density for the ideal gas equation of state (left panel) and the Abel-Nobel equation of state with a co-volume constant of $\boldsymbol{b}=\mathbf{7 . 6 9 1} \times \mathbf{1 0}^{-3} \mathrm{~m} / \mathrm{kg}$ (right-panel). A positive error means that the calculated density is higher than the actual density.

When a gas is released from a source that is above the critical pressure (1.9 times the ambient pressure, for hydrogen), flow through the release (nozzle) becomes choked. This means that the pressure immediately following the nozzle remains above ambient, and the flow through the nozzle occurs at the speed of sound. The jet expands downstream of the nozzle, forming a complex shock structure before achieving ambient pressure jet, as can be seen in Figure 2. In these images, the Mach disk shock wave is about $5 \mathrm{~mm}$ downstream from the release, the atmospheric pressure turbulent jet starts downstream from the Mach disk, and the jet is much wider than the $1 \mathrm{~mm}$ diameter nozzle at this location.
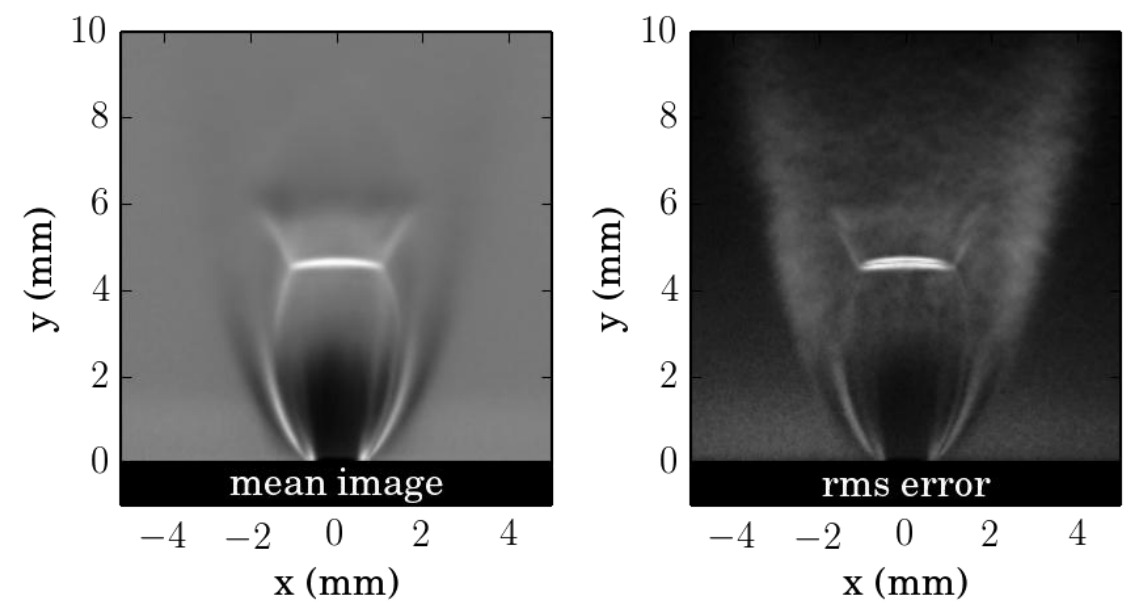

Figure 2. Example mean and rms error of 200 schlieren images of a hydrogen release from a $1 \mathrm{~mm}$ nozzle, with a stagnation pressure of 50 bar. 
In the ambient pressure, momentum-dominated region of the jet following the Mach disk, canonical centerline mole fraction decay rates are observed [12,16,17], where the inverse mean centerline concentration decays proportionally to what in this case is an effective diameter; i.e.

$\overline{x_{C L}}=K \frac{d_{e f f}}{z+z_{0}} \frac{\rho_{a m b}}{\rho_{H 2, S T P}}$,

where the effective diameter,

$d_{e f f}=d \sqrt{\frac{\rho_{e f f}}{\rho_{a m b}}}$.

In these equations, $\overline{x_{C L}}$ is the mean centerline mole fraction of hydrogen, $K$ is a proportionality constant, $z$ is the downstream distance, $z_{0}$ is an apparent source location, $d$ is the nozzle diameter, and $\rho$ is the density, where subscripts $a m b, H 2, S T P$, and eff represent the ambient fluid, hydrogen at standard temperature and pressure, and the effective source density respectively. Analogous to this approach to predicting the centerline mole fraction decay rate for a momentum-dominated jet by using the effective source diameter and thermodynamic state (density), in the 1-D integral model described earlier that can predict both momentum and buoyancy driven motion, the effective source diameter, thermodynamic state, and velocity are used as boundary conditions. Our current work is focusing on accurately determining the appropriate boundary conditions for input to the plume/jet model, as there is still much ambiguity in the literature regarding this notional nozzle approach $[15,18,19]$.

\subsubsection{Flame model}

One major hazard from an unintended release of hydrogen is a hydrogen jet flame, which can cause burns from radiant heat flux and the high flame temperature. Our approach to modeling a hydrogen flame is similar to the plume/jet model, where the radial profiles normal to the centerline for several conserved quantities are assumed to have a Gaussian profile. The conservation equations for the mass, momentum, and mixture fraction along the flame length form a system of first-order ordinary differential equations that are integrated along the centerline. Entrainment due to buoyancy and momentum are considered, and a local equilibrium is assumed to determine the heat release in the flame. The flame model results in predictions of the velocity, density, mixture fraction, temperature, and trajectory of flame, which can have significant curvature due to buoyancy [20].

In addition to the temperature field, the radiant heat-flux from a hydrogen flame poses a significant hazard, and must be appropriately modeled. The radiant energy emitted by the hydrogen flame is related to the combustion gas properties, and the characteristic flame residence time [21]. Because the flame is curved in the model, this radiant energy is assumed to be distributed along the length of the flame, and a weighted multi-point source model is used to calculate the heat flux field [22]. With an appropriate choice of boundary conditions (similar to the plume model, a notional nozzle model is needed to provide an effective source for this model), the flame and heat flux model has compared well to experimental data [20].

\subsubsection{Overpressure model}

If an unintended release of hydrogen is allowed to accumulate indoors before ignition, a deflagration or detonation can cause a significant overpressure that damages structures or results in injury or death to people. Our model follows the approach of Bauwens et. al [23], wherein the adiabatic expansion due to combustion of the flammable mixture is responsible for the pressure rise within an enclosure. To calculate the amount of flammable mixture in the enclosure, a time-dependent, layered accumulation model [24] is coupled to the plume/jet model described in section 2.1.1. This model has compared favorably to overpressure data from a scaled warehouse test [25]. 


\subsection{Impact}

Guidance for the siting of hydrogen fueling stations in the United States is established in the National Fire Protection Agency's Hydrogen Technologies Code (NFPA 2 [26]). The hydrogen behavior work discussed in this section can affect this document and how it is implemented in two ways. First, analyses using these behavior models can inform updates to the new versions of relevant codes and standards; for example, the guidance suggested by LaChance et. al [27] was able to scientifically justify the reduction of several separation distances related to the storage of gaseous hydrogen (GH2) in the 2011 release of the NFPA code. These changes to the code have enabled deployment of hydrogen fueling infrastructure; by one account, about $20 \%$ of existing fueling stations in California can satisfy the requirements of the 2011 version of NFPA 2 for GH2 storage, while none of the 70 analyzed sites could meet the requirements of the 2005 version [28]. The second way this work can have an impact on the siting of hydrogen fueling stations is through the performance-based option for design certification described in chapter 5 of NFPA 2. As discussed further in the next section, behavior models are being integrated into a quantitative risk assessment tool that engineers and designers can use to justify performance-based decisions when working with authorities having jurisdiction (AHJs) to qualify a given design.

\section{QUANTITATIVE RISK ASSESMENT (QRA)}

\subsection{Role of QRA}

Considerations of RCS for use of hydrogen as a transportation fuel are influenced by industrial gas, oil and gas and nuclear power industries, which have historically worked with hydrogen. The RCS requirements used in these industrial applications are generally conservative and often hinder the further promulgation of hydrogen fueling infrastructure. To address these limitations, and to enhance the scientific basis for codes and standards, there has been a push toward using risk information to develop and revise hydrogen-specific codes, such as NFPA 2. Use of risk information in NFPA 2 is in line with general international trend toward more flexible, yet defensible codes and standards [29,30].

QRA is an important tool for maintaining the safety and the commercial viability of hydrogen as a transportation fuel, and is thus expected to play an increasing role as this hydrogen technology shifts toward market deployment. It offers a framework for using the best science and engineering models and data to develop codes and standards, as well as to facilitate the design and permitting process for hydrogen fueling stations. From the hydrogen safety research community perspective, one of the key tasks is to translate fundamental scientific findings into practical, user-friendly tools, which are easily applied in daily work. QRA can play a key role in supporting safety decisions in areas with large numbers of relevant variables.

\subsection{QRA Methodology}

The general QRA framework for hydrogen uses a combination of probabilistic and physical (behavior) models to assess the likelihood and impacts of various hydrogen release and ignition scenarios, which can lead to thermal and overpressure hazards. The primary scenario develops from the release and subsequent ignition of hydrogen. The two main hazards are exposure to thermal effects from jet fires and deflagrations and exposure to overpressures from deflagrations and detonations. Both of these hazards can affect people, property, structures, and the environment directly or indirectly. Several models with data linkages are typically needed to characterize the physical effects of the hazards. Information from the physical effect models is passed into probit functions used to calculate consequences in terms of harm or loss.

While general QRA methods are applicable to hydrogen systems, more widespread use of QRA for code revisions has previously been limited due to gaps in available data and models relevant to hydrogen systems [31,32,33,34]. More recently, researchers have found that QRA for hydrogen applications is further limited due to the variety of models required to perform a complete QRA [34]. These deficiencies prevent the code development committees from using QRA to suggest revisions to 
the code and prevent AHJs from evaluating design variances to the code that are requested by station builders due to site-specific constraints. However, research progress in models, data and tools is actively addressing many of these gaps.

\subsubsection{Methodology and tools}

Most hydrogen QRAs follow the same general series of modeling steps shown in Figure 3 (although steps are omitted in some analyses). Critical differences are found in the specific models and data used for each step, and in the level of integration of all of steps. In most current work, traditional QRA models (i.e., Event Trees, Fault Trees, parts counts, etc.) [35,36,37,38,39,40,41] or extended QRA techniques (e.g., Bayesian Networks) [42,43] are used to model the scenarios and root causes, and various reduced-order models and CFD models are used for consequence calculations. The emergence of fast-running behavior models opens the door for use of advanced QRA approaches (i.e., dynamic PSA [probabilistic safety assessment]), including Event Sequence Diagrams [31], Discrete Dynamic Event Trees, various sampling and simulation-based QRA and PSA models $[44,45,46]$.

Efforts to streamline and standardize the methodologies used for hydrogen QRA have largely focused on the development of software tools to facilitate user-friendly access to state-of-the-art models [47,48]. These efforts are being coordinated under the auspices of IEA HIA Task 31/37. Coordinated, complementary efforts are ongoing at multiple international research institutions, including Sandia National Laboratories (SNL), Karlsruhe Institute of Technology (KIT), and University of Ulster (UU).

SNL is developing a QRA tool called HyRAM (Hydrogen Risk Assessment Models [49]) specifically to enable risk assessment for defensible, science-based codes and standards $[47,50,51]$. HyRAM integrates relevant behavior models and probabilistic models into a single analysis framework. This tool is intended to enable access to state-of-the-art models and a framework necessary for risk assessment of hydrogen transportation infrastructure. In particular, industry experts, including codes and standards developers and station designers, who need fast running, high-level insights rather than expensive and resource-intensive numerical simulations (i.e, CFD), will benefit from this unique software. At the same time, the tool may serve as the basis for the development of risk-informed codes, such as NFPA 2 and ISO 19880-1. The HyRAM tool (as well as the tools being developed by HySafe and members of IEA HIA Task 37) brings together the expertise of the international hydrogen safety research community and puts the knowledge in the hands of the decision makers who ensure the safety of the hydrogen industry.

The HyRAM effort focuses on developing a flexible platform for integrating hydrogen-specific behavior and probabilistic models and data for QRA. HyRAM currently incorporates traditional QRA approaches, with planned efforts to extend to a dynamic QRA framework with embedded simulation in the longer term. The HyRAM framework includes generic hydrogen data (Section 3.2.2) as a default option. In addition to behavior models for the main hazards (Section 2.1), HyRAM includes harm models for thermal and pressure effects as discussed in Section 3.2.3. The modular configuration of the HyRAM platform is intended to enable the adoption of additional hazard models that are developed by complementary efforts, such as those mentioned above.

\subsubsection{Probability data and models}

Probabilistic models and data are used to simulate potential accident scenarios and root causes of hydrogen releases. LaChance has addressed the need for hydrogen-specific data for frequency of releases from multiple of types components through combination of limited hydrogen-specific data with generic industry data [27]. Each combination of component type and release size is associated with a lognormal distribution for frequency of leaks (per year). Currently there is little data on likelihood or frequency of occurrence of releases from non-leak failure mechanisms (e.g., failure to operate, faulty indication). Ongoing efforts to develop databases of hydrogen accidents and nearmisses show promises as additional information that could be used to develop structured data for hydrogen-specific component failures [52]. 
One continuing area of research is into the probability of ignition of a release. Current ignition probability models are look-up tables, which assign mean probability of immediate and delayed ignition as a function of hydrogen release rate; probabilities are derived from expert judgment [53,54]. Ongoing efforts on the physical modeling side show promise for improving the modeling of ignition [15], although additional work must be conducted to pull physics models into a QRA framework; this type of challenge motivates the transition to a dynamic QRA capable of interfacing with physics simulation models.

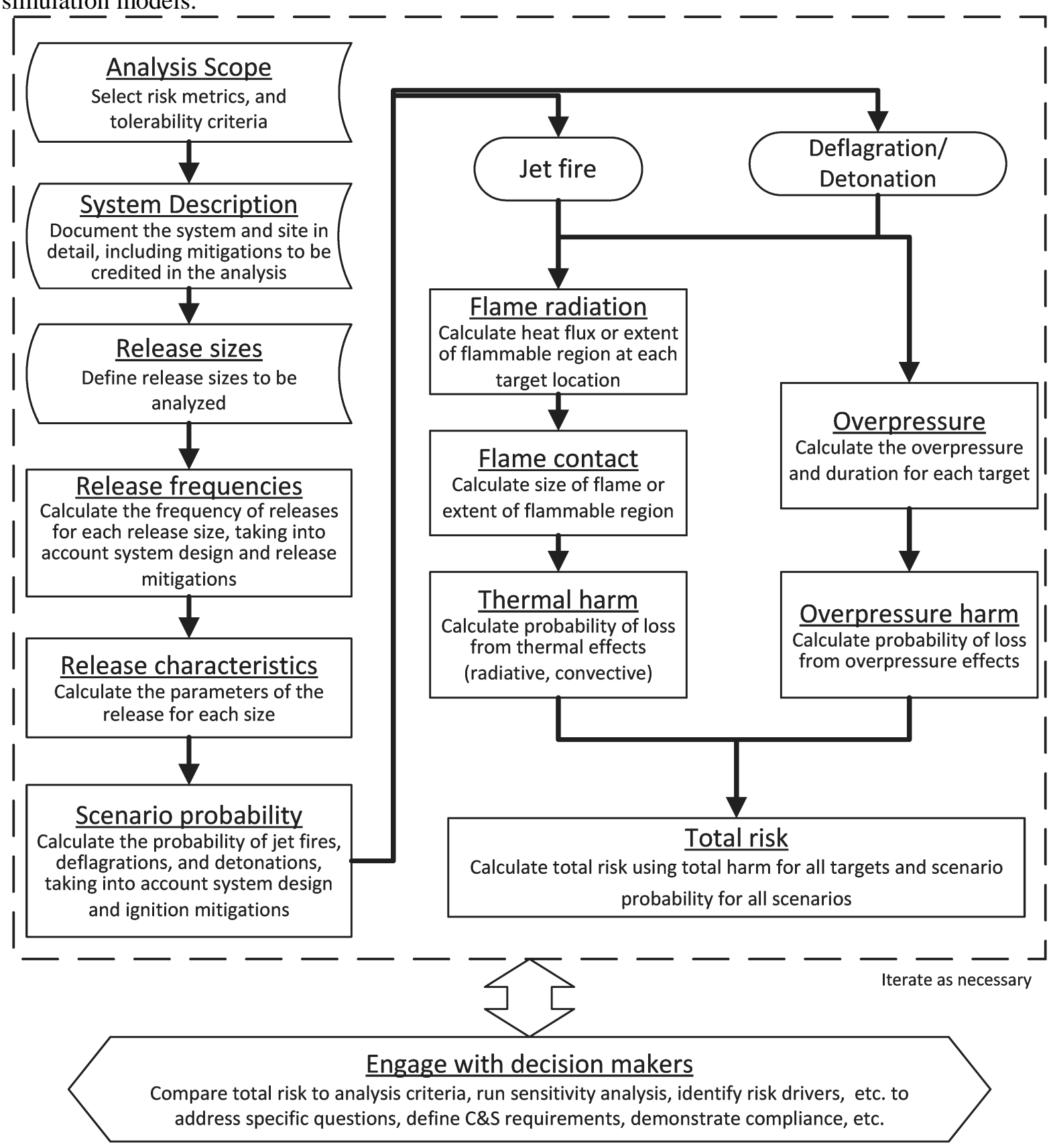

Figure 3: Complete framework for performing QRA for decision support in hydrogen applications.

\subsubsection{Consequence models and harm models}

Significant progress has been made in development and validation of fast-running behavior models for a range of physics relevant in hydrogen systems, as discussed in section 2.1. These fastrunning behavior models form the foundational consequence models necessary for modeling two of 
the primary hazards associated with hydrogen systems, namely jet fires and deflagrations. Understanding and modeling detonations in addition to jet fires and deflagrations is also ongoing work $[55,56]$.

Researchers have also established harm models and harm criteria for the two main damaging physical effects of hydrogen, thermal and overpressure events. Efforts have focused on harm to humans and structures. Harm models are criteria have largely been developed by reference to criteria and models used within other process industries. LaChance et al. [57] surveyed the available models and found that two approaches are most prevalent: use of specific, deterministic harm criteria, and use of probit functions to regress the probability of harm against the magnitude of a physical effect. In general, models in this area address thermal effects resulting from radiative heat flux from flames (e.g., jet fires, deflagrations) for a specified duration. Thermal effects from conduction are conservatively assumed to result in maximum harm. Harm from overpressure effects is modeled as a function of the peak overpressure, and sometimes also the impulse resulting from a deflagration or detonation.

\subsection{Impact}

QRA was used to inform separation distances in the 2011 revision to NFPA 2 [41] by establishing boundary conditions as inputs to the behavior models (described in Section 2), which in turn determined the profile of the physical hazards (heat and concentration contours). QRA was also used to address size limits of indoor fueling rooms in the 2014 code revisions [31]. NFPA2 also contains performance-based rules (chapter 5), which permit the use of analytical methods such as QRA to demonstrate that a system is as safe as or safer than a system compliant with the prescriptive requirements in the code [58].

Internationally, ISO TC197 is actively pursuing use of a QRA-based methodology to determine safety distances in ISO 19880-1 as well as codification of a QRA-based method for performancebased compliance. Similar work is being planned during the upcoming revision cycle of the Canadian Hydrogen Installation Code (CHIC) within the 2014-15 timeframe. There has been a push initiated within IEA HIA (Hydrogen Implementing Agreement) Tasks 19, 31, and 37 on hydrogen safety driven by SNL and HySafe toward using risk information as well as simplified engineering tools for hazard assessment. While QRA has already had an impact on RCS domestically and internationally, improvements in the approaches and tools can make this method even more accessible and useful to decision makers in the hydrogen community.

\section{MATERIALS COMPATIBILITY}

\subsection{Hydrogen-materials interactions}

Hydrogen is unique relative to other fluids: it strongly interacts with surfaces, has a relatively high solubility and easily diffuses into most materials at room temperature. In non-metals, hydrogen may diffuse as a molecule, although relatively little is known about the interaction of molecular hydrogen in materials. Molecular hydrogen can generate non-reversible damage in elastomers, if the elastomer becomes super-saturated (e.g., during de-pressurization). Other hydrogen-induced phenomena, such as potential for plasticization in non-metals, have not been observed, but also have not been adequately studied [59]. In contrast, hydrogen tends to dissociate on metal surfaces, diffusing into the metal as a single atom. As hydrogen diffuses into the metal, it interacts with the microstructure affecting properties such as ductility, fracture resistance, and fatigue crack growth; these interactions are generically referred to as hydrogen embrittlement [60]. Hydrogen in materials can evolve from many sources, including corrosion, electrochemical environments and ambient moisture, as well as direct exposure to environments containing gaseous or liquid hydrogen, such as storage and distribution of hydrogen fuels. Consequently, hydrogen effects have been studied extensively for many decades, although the physics of the interactions are still a topic of debate and the available engineering data remains incomplete.

In the context of hydrogen fuels, a growing database of materials properties measured in gaseous hydrogen is now available for a range of materials that are important for handling and delivering 
gaseous hydrogen. The ductility, fracture and fatigue properties of virtually all metals are degraded by exposure to gaseous hydrogen. From an engineering perspective, the suitability of a particular material in hydrogen service depends on a number of factors related to

- materials variables: the condition of the material, including strength and microstructure;

- mechanical variables: the structural integrity of the component, including magnitude of both static and fatigue stresses, as well as the size, distribution and population of structural defects;

- environmental variables: time, temperature, pressure and gas purity.

\subsection{Hydrogen embrittlement}

The hydrogen community has struggled with identifying materials that are "compatible with hydrogen". This challenge partly stems from the false notion that the suitability of materials for specific applications can be established from a universal materials compatibility test. The properties of virtually all metals are degraded in hydrogen environments; the appropriateness (or suitability) of a material in a hydrogen environment depends on the design of the component and the service conditions. While there are clearly some materials that should not be used in hydrogen, many structural materials can be used safely with appropriate design consideration, despite degradation of properties in hydrogen environments. Transportable gas cylinders are a ubiquitous example of a component manufactured from a material that shows degradation of properties in hydrogen environments, but is used safely to transport gaseous hydrogen. Standard transportable gas cylinders are manufactured from Cr-Mo steels. Fatigue crack growth rates in Cr-Mo steels are accelerated by an order of magnitude under some loading conditions compared to rates air $[61,62,63,64]$. Yet, the design requirements for transportable gas cylinders make them suitable for this specific high-pressure hydrogen application [65]. Steel pipelines represent another example where fracture resistance is degraded and fatigue crack growth rates are accelerated in gaseous hydrogen environments $[66,67]$, however, thousands of kilometers of pipeline are used to transport hydrogen.

The accommodation for hydrogen embrittlement in transportable gas cylinders and steel pipelines is substantially different, despite the similarity in response of the material to gaseous hydrogen environments. Transportable gas cylinders for hydrogen and for inert gases (such as nitrogen) are designed the same. In other words, there is no special accommodation for hydrogen embrittlement, even though the material shows significant effects of hydrogen on the properties. In contrast, pipelines are typically operated at lower pressure with hydrogen than they would be with other fluids, while the properties of pipelines in gaseous hydrogen are quite similar to Cr-Mo steels in the same environment. The difference in accommodation for these two materials and applications undoubtedly stems from multiple factors including the design methodology, service experience and consequence of a failure; however, it is clear that these decisions were not made based on engineering analysis, since, until recently, there has been insufficient materials data generated in gaseous hydrogen to inform engineering analyses of pressure vessel and pipeline structures.

The standardization of the testing methods to evaluate engineering properties in high-pressure gaseous hydrogen enables robust structural integrity assessment of hydrogen infrastructure as an alternative to experience-based guidance. Additionally, access to standardized test methods and data enables informed decisions on materials selection and the consideration of new materials for hydrogen service. In addition to the materials variables and the mechanical variables, robust test methods must also specify subtle environmental conditions to accelerate the testing. For example, fatigue in hydrogen environments is sensitive to the frequency of the stress cycle, however, pressure/stress cycles in infrastructure that operates for decades cannot be practically tested at the same frequency as the application. Therefore, robust understanding of rate effects is critical to evaluating performance of materials in hydrogen. Also, impurities (such as oxygen) at relatively low levels can mitigate the effects of hydrogen under certain circumstances [68]. The role of impurities underscores the importance of appropriate purging processes when testing materials to ensure the reliability of the test results, since residual air in the test system can affect the measured fracture and fatigue response of the materials. On the other hand, with proper understanding, the beneficial effects of impurities can be 
harnessed to mitigate the effects of hydrogen on fracture and fatigue of delivery and storage infrastructure, thus enabling technology deployment.

Several recent developments in codes and standards have been enabled by research activities in the Hydrogen Effects on Materials Laboratory (HEML) at SNL. The ASME Boiler and Pressure Vessel Code added performance-based design requirements for high-pressure tanks for storage of gaseous hydrogen. These design requirements include specification of fracture and fatigue methods for testing in gaseous hydrogen, which were adopted from existing testing standards. The methods were critically evaluated and improvements suggested by the research team in HEML [69,70]. In the process of evaluating the test methods, a grade of Cr-Mo pressure vessel steel (ASME SA-372 Grade J) was evaluated $[61,64]$. The data generated as part of the evaluation remains the only ASME codecompliant data set for high-pressure vessels.

While critical assessment of testing methods and the resulting data are necessary to fully understand the impact of evolving methods, component testing also aids validation of the methods. For example, full-scale pressure vessel testing was conducted to evaluate the fatigue crack growth design method in the ASME code and the failure behavior of the vessels. In that study, defects were machined in the inside of two pressure vessel designs, and the vessels were pressure cycled with hydrogen to failure, showing that the fatigue crack growth methodology is conservative and that the vessels leaked before bursting $[63,65]$. In addition, critical assessment of the results suggested an alternative design analysis methodology for hydrogen pressure vessels: stress-based fatigue analysis. The stress-based fatigue method has become the basis for one of the performance-based options in a relatively new materials qualification standard from CSA Group: CHMC1, Test Method for Evaluating Material Compatibility in Compressed Hydrogen Applications.

\subsection{Impact}

The Hydrogen Effects on Materials Laboratory at SNL has contributed to several recent codes and standards developments related to materials qualification for hydrogen service. These contributions include active participation in the activities at ASME, CSA Group, SAE as well as evolving discussions with ASTM International. As mentioned above, the testing guidance in Division 3 of Section VIII of the ASME Boiler and Pressure Vessel Code (Article KD-10) was influenced by results on Cr-Mo steels [61,64,69,70]; similarly, the hydrogen piping and pipeline code (ASME B21-12) was guided by these and additional studies on carbon steels $[66,67]$. The testing methodologies in the CSA CHMC1 standard were likewise guided by these same studies and additional efforts to evaluate stressbased fatigue methodologies [71,72]. Standardized test methods for hydrogen fuel systems (SAE J2579 and CSA HPIT1) are based on full-scale pressure vessel testing [63,65]. A draft ASTM International standard for fracture testing is based on this collective work, as well as international collaboration [73,74]. Staff from HEML also participate in discussions in Europe and Asia with the intent of working toward the harmonization of performance-based materials qualification for fatigue service. In addition to directly impacting the requirements of the testing methodologies that are written in various codes and standards, the scientific output of the experimental activities in HEML provide critical data necessary to advance technology deployment, as with ASME code-compliant steel pressure vessels for hydrogen service at pressure up to $100 \mathrm{MPa}[61,64]$. Other activities include enabling broader choices for materials of construction in hydrogen applications through engineering design evaluation and alloy design. Deep scientific understanding of hydrogen embrittlement processes enables not only materials selection, but also innovative strategies to control the negative impacts of hydrogen on materials.

\section{FUEL QUALITY}

\subsection{Hydrogen fuels}

Hydrogen fuels can be obtained from various sources, including steam reforming or partial oxidation of fossil fuels (mainly natural gas), gasification of coal or biomass, electrolysis of water, photo-electrochemical water splitting, and many others. Today, $95 \%$ of hydrogen production comes 
from fossil fuels, primarily by steam reforming of natural gas. The main impurities present in hydrogen obtained from fossil fuel sources include carbon monoxide $(\mathrm{CO})$, carbon dioxide $\left(\mathrm{CO}_{2}\right)$, hydrogen sulfide $\left(\mathrm{H}_{2} \mathrm{~S}\right)$, ammonia $\left(\mathrm{NH}_{3}\right)$, methane $\left(\mathrm{CH}_{4}\right)$ and other hydrocarbons [75]. Contaminants, such as $\mathrm{H}_{2} \mathrm{~S}, \mathrm{CO}$, and $\mathrm{NH}_{3}$, even at the part per billion (ppb) levels in the fuel stream, have been shown to affect the overall performance and durability of polymer electrolyte membrane fuel cells (PEMFC), which are used in fuel cell vehicles [76,77]. Research suggests that there are two primary degradation mechanisms by which the impurities affect the performance of fuel cell membrane electrode assemblies (MEAs). First, the contaminant may lower the ionic conductivity in the catalyst layer and/or in the bulk membrane. This particular phenomenon has been observed and attributed to cationic substitution of the impurity ion with proton in the ionomer phase. Secondly, the contaminants can lower the performance of the electrodes due to adsorption on the electro-catalyst surface [76,77]. The effect of these contaminants generally become more pronounced as the platinum loadings and or the ionomer content are lowered; fuel cell systems are expected to maintain high performance at electro-catalyst loadings as low as $0.1 \mathrm{mg} \mathrm{Pt} / \mathrm{cm}^{2}$ at the cathode and $0.025 \mathrm{mg} \mathrm{Pt} / \mathrm{cm}^{2}$ at the anode [78].

PEMFC testing with contaminant mixtures have revealed performance losses due to $\mathrm{H}_{2} \mathrm{~S}, \mathrm{NH}_{3}$, and $\mathrm{CO}[79,80]$. These impurities are referred to as 'critical constituents'. Recently published hydrogen fuel standards (ISO 14687-2 and SAE J2719) set the limits of the critical contaminants at levels up to $4 \mathrm{ppb}_{2} \mathrm{~S}, 200 \mathrm{ppm} \mathrm{CO}$, and $100 \mathrm{ppb} \mathrm{NH}_{3}$ [81,82]. ISO Technical Committee 197, Work Group 12 (ISO TC197 WG12) was formed to determine the acceptable level of non-hydrogen constituents that do not degrade the performance of PEMFCs. In addition, WG12 members agreed to test PEMFCs using a 'Common MEA' loaded at 0.1 and $0.4 \mathrm{mg} \mathrm{Pt} / \mathrm{cm}^{2}$ under various operating conditions and with specified levels of the critical contaminants. Additionally, independent studies have evaluated the performance of MEAs loaded with $0.2 \mathrm{mg} \mathrm{Pt} / \mathrm{cm}^{2}$ operating at constant current. More recent studies have started examining the effect of impurity concentration, potential cycling, and ultra-low Pt-loading on PEMFC performance [83].

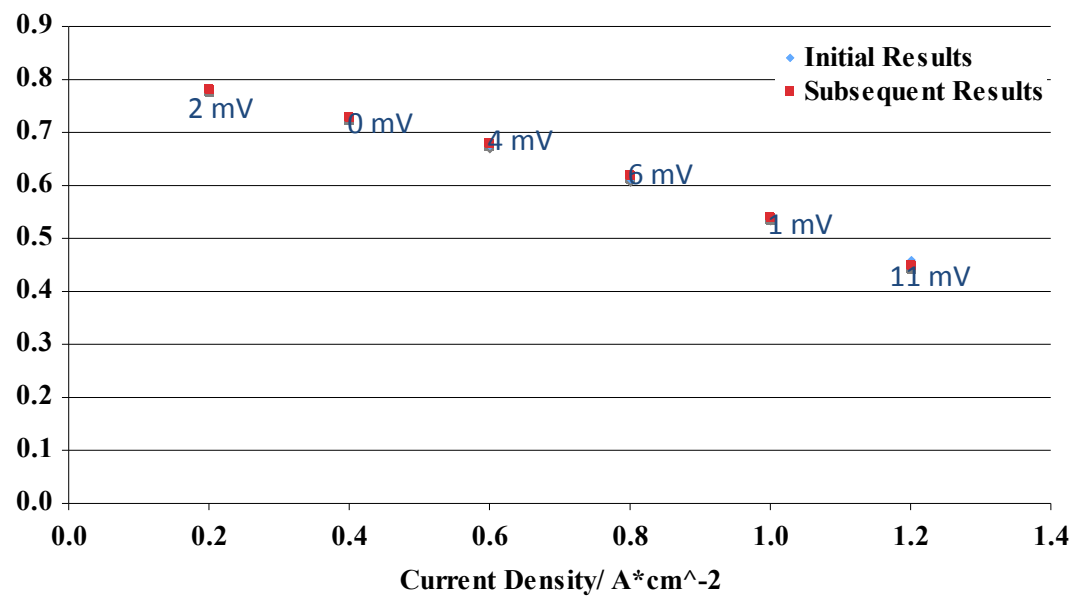

Figure 4. Verification testing before and after round robin tests were completed by participants $\left(0.2 \mathrm{mg} P t / \mathrm{cm}^{2}\right.$, temperature of $80^{\circ} \mathrm{C}$, pressure of 1.7 bar gauge relative to sea-level, fully humidified).

\subsection{Evaluation of fuel quality on PEM fuel cells}

\subsubsection{Round robin testing}

A round robin was developed to validate the reproducibility of experiments designed to measure the effect of impurities on PEMFC performance at different test facilities. The round robin included participation from four universities and two national laboratories. To this end, a fuel cell test article 
was developed at Los Alamos National Laboratory (LANL) to enable a common platform for testing. The $50 \mathrm{~cm}^{2}$ active-area MEA was prepared using $\mathrm{a} \approx 50 \mu \mathrm{m}$ thick Nafion ${ }^{\circledR}$ membrane and $0.2 \mathrm{mg} \mathrm{Pt} / \mathrm{cm}^{2}$ at each electrode. The fuel cell hardware was sent to the test labs along with detailed testing instructions. The tests performed included 'gross leak' test, hydrogen crossover measurements, cyclic voltammetry, and polarization curves. After testing, the article was shipped to the subsequent tester. After all of the test facilities completed their tests, the test article was returned to LANL for a re-test. Figure 4 shows current-voltage curves with excellent reproducibility for the test article operated at $80^{\circ} \mathrm{C}$ with 25 psig back pressure and $100 \%$ relative humidity. The stoichiometric gas flows were $83 \%$ utilization for hydrogen and $50 \%$ for the air. Tests were conducted in constant current mode while the voltage at each current set point was recorded. The results indicated less than $6 \mathrm{mV}$ of deviation along the entire polarization curve, with the exception of $11 \mathrm{mV}$ of deviation in the high current region (possibly due to liquid water). These results show no degradation of the performance before and after the round robin testing, therefore, it was possible to assimilate the results from all of participants for a direct comparison. Figure 5 shows excellent agreement between the results from the participants at an operating temperature of $60^{\circ} \mathrm{C}$; similar agreement was found for other testing conditions.

\subsubsection{Effect of CO on performance}

The interaction between carbon monoxide and platinum electrodes has been extensively studied in the past, both in half-cells and operating fuel cells $[84,85,86]$ and mitigation strategies were identified [87,88]. All studies are in agreement that CO adsorbs onto Pt sites, blocking hydrogen dissociation. To date, most studies have focused on either the fundamental reaction kinetics or the development of mitigating strategies such as: variation of the platinum loading, humidification or operating temperature, the use of platinum-alloys, and/or oxygen introduction into the anode feed-stream. These studies were conducted with parts per million ( $\mathrm{ppm}$ ) levels of $\mathrm{CO}$ and anode loadings at or above $0.2 \mathrm{mg} \mathrm{Pt} / \mathrm{cm}^{2}$. However, the actual fuel cell tolerance to $\mathrm{CO}$ using low platinum anode loading $\left(<0.2 \mathrm{mg} \mathrm{Pt} / \mathrm{cm}^{2}\right)$ has not been reported. To meet the desire to further reduce Pt loading, the CO tolerance of PEMFCs is being explored at various cell temperatures using anode platinum loadings of 0.1 and $0.05 \mathrm{mg} / \mathrm{cm}^{2}$.

In order to study the effect of $\mathrm{CO}$ concentrations on fuel cell performance, anodes loaded with either 0.05 or $0.1 \mathrm{mg} \mathrm{Pt} / \mathrm{cm}^{2}$ were subjected to several different $\mathrm{CO}$ concentrations at temperature of $80^{\circ} \mathrm{C}$, using hardware manufactured by Fuel Cell Technologies Inc. (Albuquerque NM) and operated with constant current density of $1 \mathrm{~A} / \mathrm{cm}^{2}$. The dosage in each experiment was kept constant $(20 \mathrm{ppm}$ hr CO) by varying both concentration and exposure times. Cyclic voltammetry (CV) was used to clean the platinum surface after $\mathrm{CO}$ exposure following each experiment, enabling the use of the same cell for subsequent $\mathrm{CO}$ exposures. Experimental results with an anode loading of $0.1 \mathrm{mg} . \mathrm{Pt} / \mathrm{cm}^{2}$ for differing concentrations of $\mathrm{CO}$ revealed a zero loss concentration of $\mathrm{CO}$ at $0.5 \mathrm{ppm}$ for these test conditions (extrapolation of voltage loss vs. CO concentration curve to zero loss). Similar experiments were performed for an anode loading of $0.05 \mathrm{mg} . P \mathrm{t} / \mathrm{cm}^{2}$ at temperature ranging from $45^{\circ} \mathrm{C}$ to $80^{\circ} \mathrm{C}$. As summarized in Figure 6, the $\mathrm{CO}$ tolerance improves with temperature: cells operated at temperature of $80^{\circ} \mathrm{C}$ show less than $1 \%$ voltage loss at $\mathrm{CO}$ concentration as high as $100 \mathrm{ppb}$ for this low Pt loading. It should be noted that the effect of $\mathrm{CO}$ is reversible and dependent on the potential. Moreover, complete recovery can be achieved via cycling to high potentials (e.g., via a start/stop operation). 


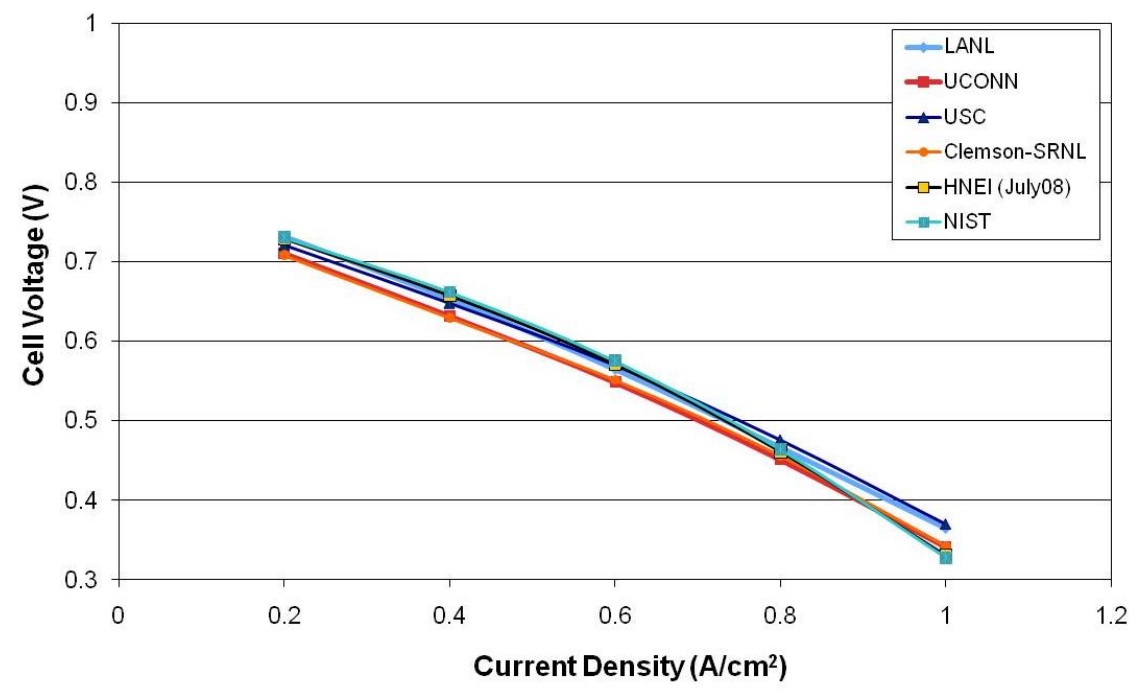

Figure 5. Results obtained at $60^{\circ} \mathrm{C}$ from all of the round robin participants (ambient sea-level pressure, fully humidified).

\subsubsection{Effect of $\mathrm{H}_{2} \mathrm{~S}$ on performance}

Sulfur containing compounds are expected to be present in any hydrogen derived from fossil fuel sources. Although there are several different species of sulfur contaminants that can arise; the focus on current testing has been hydrogen sulfide in the anode stream. Hydrogen fuel specifications $[81,82]$ allow for the presence of minute concentrations of sulfur compounds up to $4 \mathrm{ppb}$. These specifications to some extent were based on the state of the art detection limits at the time the specifications were written. For evaluating the impact of sulfur, sulfur compounds were intentionally introduced as a mixture along with the fuel in an operating fuel cell. Several parameters such as relative humidity, operating modes (i.e. constant voltage, cyclic voltage variations or constant current) and catalyst loadings were varied to probe their influence on fuel cell performance. When the sulfur compound was introduced to either the anode or cathode a negative impact was observed due to electro-catalyst poisoning $[80,89,90]$. The impact became more severe under certain operating conditions and as exposure time increases. As an example, the voltage losses observed under $1 \mathrm{~A} / \mathrm{cm}^{2}$ after introducing $4 \mathrm{ppb} \mathrm{H}_{2} \mathrm{~S}$ for 100 hours in the anode at $100 \%$ relative humidity were approximately $30 \mathrm{mV}$; they were magnified to $\sim 70 \mathrm{mV}$ in an identical cell operating at $50 \%$ relative humidity. Further analyses, using cyclic voltammetry, show a difference in the amount of sulfur coverage on the platinum surface as the fuel cell operating conditions were varied. The performance loss due to sulfur adsorption is not as easily recoverable as $\mathrm{CO}$ adsorption and requires more extensive voltage cycling at voltages typically $>0.85 \mathrm{~V}$.

\subsection{Impact}

The fuel cell studies summarized above are aimed at supporting the revision of hydrogen fuel cellrelated codes and standards. This work shows that the effect of impurities on fuel cell performance is influenced by the cell operating conditions. While impurity levels of $\mathrm{CO}$ and $\mathrm{H}_{2} \mathrm{~S}$ specified in the fuel quality standards will have an impact on the fuel cell performance at low Pt loadings, these effects can be significantly mitigated when operating at high temperatures and high RHs and during start/stop operations. 


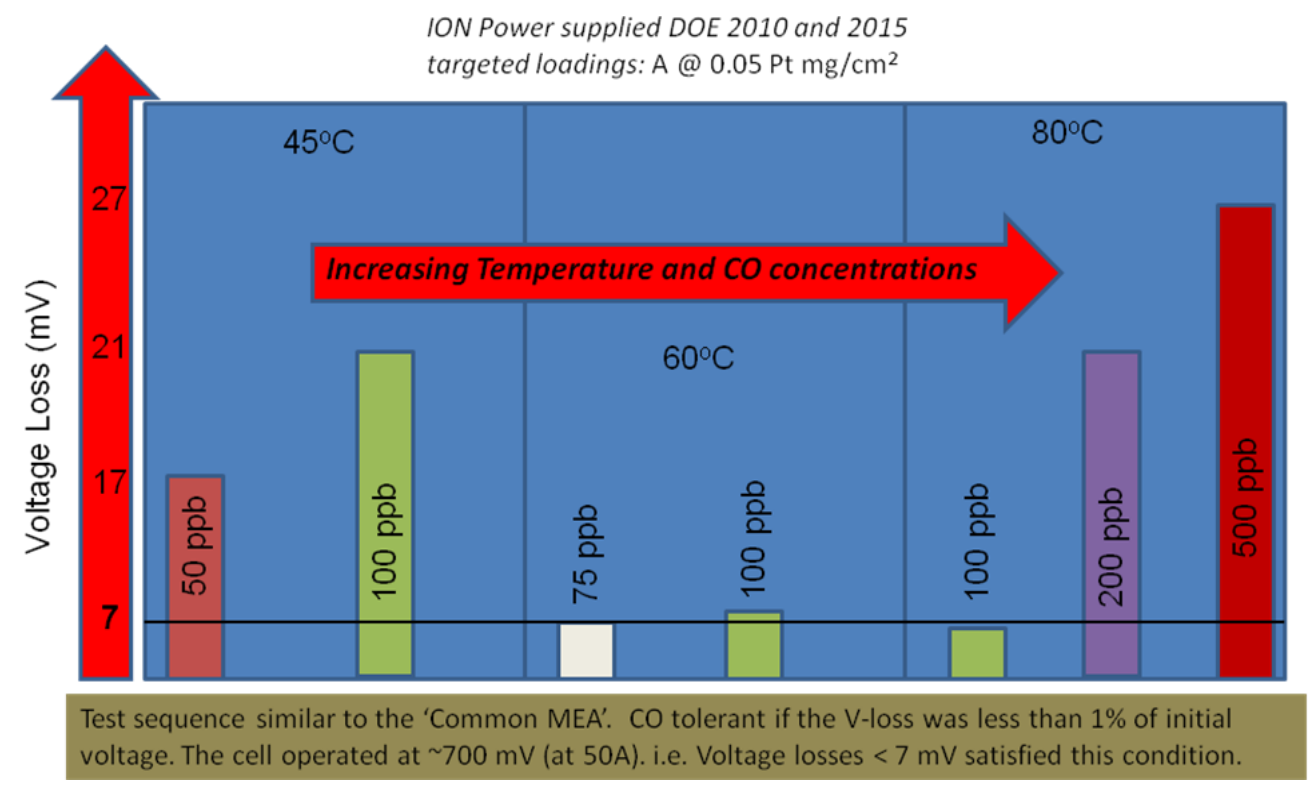

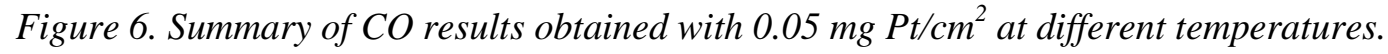

\section{SUMMARY}

The rapid advancement of codes and standards for hydrogen technologies has been facilitated by the use of scientific principles in the development and revision of these documents. Advances in four key areas are summarized in this report:

- Reduced-order numerical models of high-pressure plumes/jets and flames have been used to inform safety codes for hydrogen fueling infrastructure, such as NFPA; additional models of dispersion, deflagration and detonation will enable safety analyses for enclosed spaces.

- QRA framework and tools, such as HyRAM, enable risk assessment of hydrogen infrastructure and provide a real-time platform to:

$\circ$ inform design decisions

○ justify variances to existing prescriptive code rules

- enable science basis for revision to code requirements.

- Development of testing methods for evaluating the performance of structures in hydrogen environments enables structural integrity analysis of hydrogen infrastructure and the safety basis for its deployment.

- Advancement of harmonized test methods for characterizing the impact of impurities on the performance of PEMFCs enables revision of fuel quality standards.

\section{ACKNOWLEDGMENTS}

The Fuel Cell Technologies Office (FCTO) of the U.S. Department of Energy (DOE) supports the development of science-based codes and standards through the Safety, Codes and Standards program element. The authors gratefully acknowledge funding from FCTO to support the work described in this report. Sandia National Laboratories is a multi-program laboratory managed and operated by Sandia Corporation, a wholly owned subsidiary of Lockheed Martin Corporation, for the U.S. 
Department of Energy's National Nuclear Security Administration under contract DE-AC0494AL85000.

\section{REFERENCES}

${ }^{1}$ V.P. McConnell. Fuel cells in forklifts extend commercial reach. Fuel Cells Bulletin (September 2010) 12-19.

${ }^{2}$ V.P. McConnell. Rapid refill, high uptime: running forklifts with fuel cells. Fuel Cells Bulletin (October 2010) 12-19.

${ }^{3}$ Fuel Cells Bulletin (April 2014) 7-8; Fuel Cells Bulletin (April 2015) 10.

${ }^{4}$ Fuel Cells Bulletin (August 2011) 3; Fuel Cells Bulletin (October 2014) 5-6.

${ }^{5}$ Fuel Cells Bulletin (March 2014) 7-8.

${ }^{6}$ Fuel Cells Bulletin (July 2007) 7-8.

${ }^{7}$ K. Fosberg. Fuel cell systems provide backup power in telecom applications. Fuel Cells Bulletin (December 2010) 12-14.

${ }^{8}$ E.W. Lemmon, M.L. Huber, M.O. McLinden. NIST Standard Reference Database 23: Reference Fluid Thermodynamic and Transport Properties-REFPROP, Version 9.1. National Institute of Standards and Technology, Standard Reference Data Program, Gaithersburg, 2013.

${ }^{9}$ J.W. Leachman, R.T. Jacobsen, S.G. Penoncello, E.W. Lemmon. Fundamental Equations of State for Parahydrogen, Normal Hydrogen, and Orthohydrogen, J. Phys. Chem. Ref. Data 38 (2009) 721.

${ }^{10}$ W.S. Winters, W.G. Houf. Simulation of small-scale releases from liquid hydrogen storage systems. Int. J. Hydrogen Energy 36 (2011) 3913-3921.

${ }^{11}$ W.G. Houf, W.S. Winters. Simulation of high-pressure liquid hydrogen releases. Int. J. Hydrogen Energy 38 (2013) 8092-8099.

${ }^{12}$ W. Houf, R. Schefer. Analytical and experimental investigation of small-scale unintended releases of hydrogen. Int. J. Hydrogen Energy 33 (2008) 1435-1444.

${ }^{13}$ W.S. Winters, W.G. Houf. Simulation of small-scale releases from liquid hydrogen storage systems. Int. J. Hydrogen Energy 36 (2011) 3913-3921.

${ }^{14}$ E. Jones, T. Oliphant, P. Peterson et al. SciPy: Open source scientific tools for Python (2001).

${ }^{15}$ A.J. Ruggles, I.W. Ekoto. Ignitability and mixing of underexpanded hydrogen jets. Int. J. Hydrogen Energy 37 (2012) 17549-17560.

${ }^{16}$ A. Birch, D. Brown. The structure and concentration decay of high pressure jets of natural gas. Combust. Sci. Technol. 36 (1984) 249-261.

${ }^{17}$ C.R. Shaddix, E.S. Hecht, W.G. Houf, C.K. Westbrook, L. Tessier, F. Schneider. Evaluation of Light-Off Limits for a Novel Oxy-Combustion Process for Enhanced Oil Recovery (EOR). Energy \& Fuels 27 (2013) 3438-3445.

${ }^{18}$ E. Papanikolaou, D. Baraldi, M. Kuznetsov, A. Venetsanos. Evaluation of notional nozzle approaches for CFD simulations of free-shear under-expanded hydrogen jets. Int. J. Hydrogen Energy 37 (2012) 18563-18574.

${ }^{19}$ X. Li, E.S. Hecht, D.M. Christopher. Validation of a reduced-order jet model for subsonic and underexpanded hydrogen jets. Int. J. Hydrogen Energy 41 (2016) 1348-1358.

${ }^{20}$ I.W. Ekoto, A.J. Ruggles, L.W. Creitz, J.X. Li. Updated jet flame radiation modeling with buoyancy corrections. Int. J. Hydrogen Energy 39 (2014) 20570-20577.

${ }^{21}$ A. Molina, R.W. Schefer, W.G. Houf. Radiative fraction and optical thickness in large-scale hydrogen-jet fires. Proc. Combust. Inst. 31 (2007) 2565-2572.

${ }_{22}$ G. Hankinson, B.J. Lowesmith. A consideration of methods of determining the radiative characteristics of jet fires. Combust. Flame 159 (2012) 1165-1177.

${ }^{23}$ C.R. Bauwens, J. Chaffee, S. Dorofeev. Effect of Ignition Location, Vent Size, and Obstacles on Vented Explosion Overpressures in Propane-Air Mixtures. Combust. Sci. Technol. 182 (2010) 19151932.

${ }^{24}$ B.J. Lowesmith, G. Hankinson, C. Spataru, M. Stobbart. Gas build-up in a domestic property following releases of methane/hydrogen mixtures. Int. J. Hydrogen Energy 34 (2009) 5932-5939. 
${ }^{25}$ W.G. Houf, G.H. Evans, I.W. Ekoto, E.G. Merilo, M.A. Groethe. Hydrogen fuel-cell forklift vehicle releases in enclosed spaces. Int. J. Hydrogen Energy 38 (2012) 8179-8189.

${ }^{26}$ National Fire Protection Association, NFPA 2: Hydrogen technologies code, in: 2011.

${ }^{27}$ J. LaChance, W. Houf, B. Middleton, L. Fluer. Analyses to support development of risk-informed separation distances for hydrogen codes and standards, SAND2009-0874. Sandia National Laboratories (2009).

${ }^{28}$ A.P. Harris, D.E. Dedrick, C. LaFleur, C. San Marchi. Safety, Codes and Standards for Hydrogen

Installations: Hydrogen Fueling System Footprint Metric Development, SAND2014-3416. Sandia

National Laboratories (2014).

${ }^{29}$ S.E. Rose, S. Flamberg, F. Leverenz. Guidance Document for Incorporating Risk Concepts into NFPA Codes and Standards. Fire Protection Research Foundation.

${ }^{30}$ SFPE Engineering Guide to Performance-Based Fire Protection. 2007.

${ }^{31}$ K.M. Groth, J.L. LaChance, A.P. Harris. Early-Stage Quantitative Risk Assessment to Support Development of Codes and Standard Requirements for Indoor Fueling of Hydrogen Vehicles, SAND2012-10150. Sandia National Laboratories (2012).

32 A. Kotchourko et al. State of the art and research priorities in hydrogen safety. (Draft report) European Commission Joint Research Centre (2014).

${ }^{33}$ H.J. Pasman. Challenges to improve confidence level of risk assessment of hydrogen technologies. Int. J. Hydrogen Energy 36 (2011) 2407-2413.

${ }^{34}$ K.M. Groth, A.P. Harris. Hydrogen Quantitative Risk Assessment Workshop Proceedings, SAND2013-7888. Sandia National Laboratories (2013).

35 J.M. Ohi, C. Moen, J. Keller, R. Cox. Risk assessment for hydrogen codes and standards. Proceedings of the first International Conference on Hydrogen Safety (ICHS 2005) p. 8-10.

${ }^{36} \mathrm{~J}$. LaChance, A. Tchouvelev, J. Ohi. Risk-informed process and tools for permitting hydrogen fueling stations. Int. J. Hydrogen Energy 34 (2009) 5855-5861.

${ }^{37}$ Z. Li, X. Pan, J. Ma. Quantitative risk assessment on 2010 Expo hydrogen station. Int. J. Hydrogen Energy 36 (2011) 4079-4086.

${ }^{38}$ K.M. Groth, J.L. LaChance, A.P. Harris. Design-stage QRA for indoor vehicular hydrogen fueling systems. Proceedings of the European Society for Reliability Annual Meeting (ESREL 2013).

${ }^{39}$ O.A.A. Rosyid, D. Jablonski, U. Hauptmanns. Risk analysis for the infrastructure of a hydrogen economy. Int. J. Hydrogen Energy 32 (2007) 3194-3200.

${ }^{40}$ K. Holmefjord, G.P. Haugom. Quantitative Risk Assessment of Refuelling Station with on-site Production. Technical Report, Det Norske Veritas. Deliverable to HyApproval, WP4 (2007).

${ }^{41} \mathrm{~J}$. LaChance. Risk-informed separation distances for hydrogen refueling stations. Int. J. Hydrogen Energy 34 (2009) 5838-5845.

${ }^{42}$ G.P. Haugom, P. Friis-Hansen. Risk modelling of a hydrogen refuelling station using Bayesian network. Int. J. Hydrogen Energy 36 (2011) 2389-2397.

${ }^{43}$ H.J. Pasman, W.J. Rogers. Risk assessment by means of Bayesian networks: A comparative study of compressed and liquefied H2 transportation and tank station risks. Int. J. Hydrogen Energy 37 (2012) 17415-17425.

${ }^{44}$ K. Ham, P. Marangon Alessia andl Middha, N. Versloot, N. Rosmuller, M. Carcassi, O.R. Hansen, M. Schiavetti, E. Papanikolaou, A. Venetsanos, A. Engebø, J.L. Saw, J.-B. Saffers, A. Flores, D. Serbanescu. Benchmark exercise on risk assessment methods applied to a virtual hydrogen refuelling station. Int. J. Hydrogen Energy 36 (2011) 2666-2677.

${ }^{45}$ O.R. Hansen, P. Middha. CFD-based risk assessment for hydrogen applications. Process Safety Progress, Wiley Online Library, 2008, 27, 29-34.

${ }^{46}$ T. Skjold, D. Siccama. From Computational Fluid Dynamics to 3D Risk Management -Possibilities and Limitations. Proceedings of the Nordic Conference on Disaster Mitigation (NCDM 2013). Stavanger, Norway, 26-27 September 2013.

${ }^{47}$ K.M. Groth, A.V. Tchouvelev. A toolkit for integrated deterministic and probabilistic risk assessment for hydrogen infrastructure. Proceedings of the International Conference on Probabilistic Safety Assessment and Management (PSAM 12) 2014. 
${ }^{48}$ A.V. Tchouvelev, K.M. Groth, P. Benard, T. Jordan. A Hazard Assessment Toolkit For Hydrogen Applications. Proceedings of the 20th World Hydrogen Energy Conference (WHEC 2014).

${ }^{49}$ K.M. Groth, E.S. Hecht, J.T. Reynolds, M. Blaylock, I.W. Ekoto, G.W. Walkup. HyRAM version 1.0. Sandia National Laboratories (2016). Available at hyram.sandia.gov.

${ }^{50}$ K.M. Groth, E.S. Hecht, J.T. Reynolds. Methodology for assessing the safety of hydrogen systems: HyRAM 1.0 technical reference manual, SAND2015-10216. Sandia National Laboratories (2015).

${ }^{51}$ K.M. Groth, E.S. Hecht. HyRAM: a methodology and toolkit for quantitative risk assessment of hydrogen sysems. International Conference on Hydrogen Safety (ICHS 2015). Yokohama, Japan, 1921 October 2015. And IJHE.

${ }^{52}$ N.R. Mirza, S. Degenkolbe, W. Witt. Analysis of hydrogen incidents to support risk assessment. Int. J. Hydrogen Energy 36 (2011) 12068-12077.

${ }^{53}$ A. Tchouvelev, R. Hay, P. Benard. Comparative risk estimation of compressed hydrogen and CNG refuelling options. Proceedings of National Hydrogen Association Conference (2007).

${ }^{54}$ L. K. Rodsaetre. K. O. Holmefjord. An ignition probability model for hydrogen risk analysis. Det Norske Veritas, HYSAFE Deliverable 71 (January 2007).

${ }^{55}$ W.G. Houf, G.H. Evans, E. Merilo, M. Groethe, S.C. James. Releases from hydrogen fuel-cell vehicles in tunnels. Int. J. Hydrogen Energy 37 (2012) 715-719.

56 M. Groethe, E. Merilo, J. Colton, S. Chiba, Y. Sato, H. Iwabuchi. Large-scale hydrogen deflagrations and detonations. Int. J. Hydrogen Energy 32 (2007) 2125-2133.

57 J. LaChance, A. Tchouvelev, A. Engeb $\varnothing$. Development of uniform harm criteria for use in quantitative risk analysis of the hydrogen infrastructure. Int. J. Hydrogen Energy 36 (2011) 23812388.

${ }^{58}$ A.Lafleur, A.B. Muna, K.M. Groth. Fire protection engineering design brief template: hydrogen refuleing station, SAND2015-4500. Sandia National Laboratories (2015).

${ }^{59}$ R.R. Barth, K.L. Simmons, C. San Marchi. Polymers for Hydrogen Infrastructure and Vehicle Fuel Systems: Applications, Properties and Gap Analysis, SAND2013-8904. Sandia National Laboratories (2013).

${ }^{60}$ C. San Marchi, B.P. Somerday. Technical Reference for Hydrogen Compatibility of Materials, SAND2012-7321. Sandia National Laboratories (2012)

${ }^{61}$ B.P. Somerday, K.A. Nibur, C. San Marchi. Measurement of fatigue crack growth rates for steels in hydrogen containment components. International Conference on Hydrogen Safety (ICHS3). September 2009.

${ }^{62}$ K.A. Nibur, C. San Marchi, B.P. Somerday. Fracture and fatigue tolerant steel pressure vessels for gaseous hydrogen (PVP2010-25827). Proceedings of the ASME PVP 2010 Pressure Vessels and Piping Division Conference (PVP2010). Bellevue WA, 18-22 July 2010.

${ }^{63}$ C. San Marchi, D.E. Dedrick, P. Van Blarigan, B.P. Somerday, K.A. Nibur. Pressure cycling of type 1 pressure vessels with gaseous hydrogen. International Conference on Hydrogen Safety (ICHS 2011). San Francisco CA, 12-14 September 2011.

${ }^{64}$ B.P. Somerday, C. San Marchi, K.A. Nibur. Measurement of Fatigue Crack Growth Rates for SA372 Gr. J Steel in 100 MPa Hydrogen Gas Following Article KD-10 (PVP2013-97455). Proceedings of the ASME PVP 2013 Pressure Vessels and Piping Division Conference (PVP2013). Paris France, 14-18 July 2013.

${ }^{65}$ C. San Marchi, A. Harris, M. Yip, B.P. Somerday, K.A. Nibur. Pressure cycling of steel pressure vessels with gaseous hydrogen (PVP2012-78709). Proceedings of the ASME PVP 2012 Pressure Vessels and Piping Division Conference (PVP 2012). Toronto, Canada, 15-19 July 2012.

${ }^{66}$ C. San Marchi, B.P. Somerday, K.A. Nibur, D.G. Stalheim, T. Boggess, S. Jansto. Fracture and fatigue of commercial grade API pipeline steels in gaseous hydrogen (PVP2010-25825). Proceedings of the ASME PVP 2010 Pressure Vessels and Piping Division Conference (PVP2010). Bellevue WA, 18-22 July 2010.

${ }^{67}$ C. San Marchi, B.P. Somerday, K.A. Nibur, D.G. Stalheim, T. Boggess, S. Jansto. Fracture resistance and fatigue crack growth of X80 pipeline steel in gaseous hydrogen (PVP2011-57684). Proceedings of the ASME PVP 2011 Pressure Vessels and Piping Division Conference (PVP2011). Baltimore MD, 17-21 July 2011. 
${ }^{68}$ B.P. Somerday, P. Sofronis, K.A. Nibur, C. San Marchi, R. Kirchheim. Elucidating the variables affecting accelerated fatigue crack growth of steels in hydrogen gas with low oxygen concentrations. Acta Mater 61 (2013) 6153-6170.

${ }^{69}$ K.A. Nibur, B.P. Somerday, C. San Marchi, J.W. Foulk, M. Dadfarnia, P. Sofronis, G.A. Hayden. Measurement and interpretation of threshold stress intensity factors for steels in high-pressure hydrogen gas, SAND2010-4633. Sandia National Laboratories (2010).

${ }^{70}$ K.A. Nibur, B.P. Somerday, C. San Marchi, J.W. Foulk, M, Dadfarnia, P. Sofronis. The Relationship Between Crack-Tip Strain and Subcritical Cracking Thresholds for Steels in HighPressure Hydrogen Gas. Metallurgical and Materials Transactions A, 44A (2013) pp. 248-269.

${ }^{71}$ C. San Marchi, B. Somerday and K.A. Nibur. Fatigue crack initiation in hydrogen-precharged austenitic stainless steel. Proceedings of the 2012 International Hydrogen Conference. Moran WY, 912 September 2012.

${ }^{72}$ C. San Marchi, J.A. Zimmerman, X. Tang, S.J. Kernion, K. Thuermer and K.A. Nibur. Fatigue life of austenitic stainless steel in hydrogen environments (PVP2015-45421). Proceedings of the ASME PVP 2015 Pressure Vessels and Piping Division Conference (PVP2015), Boston MA, 19-23 July 2015.

${ }^{73}$ T. Iijima, H. Itoga, B. An, C. San Marchi, B.P. Somerday. Measurement of fracture properties for ferritic steel in high-pressure hydrogen gas (PVP2014-28815). Proceedings of the ASME Pressure Vessels and Piping Division Conference (PVP2014), 20-24 July 2014, Anaheim CA.

${ }^{74}$ T. Iijima, H. Itoga, B. An, C. San Marchi, and B.P. Somerday. Fracture Properties of a Cr-Mo Ferritic Steel in High-Pressure Gaseous Hydrogen (PVP2015-45328). Proceedings of the ASME 2015 Pressure Vessels \& Piping Conference (PVP2015), Boston, MA, 19-23 July 2015.

${ }^{75}$ E.B.F. Garzon, B. Pivovar, T. Rockward, T. Springer, F. Uribe, I. Urdampilleta, J. Valerio. Effect of Fuel and Air Impurities on PEM Fuel Cell Performance. Annual DOE Fuel Cell Program Review (2006).

${ }^{76} \mathrm{X}$. Cheng et al., A review of PEM hydrogen fuel cell contamination: Impacts, mechanisms, and mitigation. J. Power Sources 165 (2007) 739-756.

${ }^{77}$ N. Zamel, X. Li, Effect of contaminants on polymer electrolyte membrane fuel cells. Prog. Energy Combust. Sci. 37 (2011) 292-329.

${ }^{78}$ Fuel Cell Technologies Office Multi-Year Research, Development, and Demonstration Plan (2012).

${ }^{79}$ T. Rockward et al. The Effects of Multiple Contaminants on Polymer Electrolyte Fuel Cells. ECS Transactions 11 (2007) 821-829

${ }^{80}$ I. Urdampilleta et al. PEMFC Poisoning with H2S: Dependence on Operating Conditions. ECS Transactions 11 (2007) 831-842.

${ }^{81}$ SAE International. SAE J2719, Hydrogen Fuel Quality for Fuel Cell Vehicles.

${ }^{82}$ International Organization for Standardization. ISO 14687-2 (2012), Hydrogen fuel, Product specification, Part 2: Proton exchange membrane (PEM) fuel cell applications for road vehicles.

${ }^{83}$ C.Q.T. Rockward, F. Garzon, R. Mukundan. Hydrogen Fuel Quality. Annual DOE Fuel Cell Program Review (2014).

${ }^{84}$ H.S. Chu, C.P. Wang, W.C. Liao, W.M. Yan. Transient behavior of CO poisoning of the anode catalyst layer of a PEM fuel cell. J. Power Sources 159 (2006) 1071-1077.

${ }^{85}$ C.G. Farrell, C.L. Gardner, M. Ternan. Experimental and modelling studies of CO poisoning in PEM fuel cells. J. Power Sources 171 (2007) 282-293.

${ }^{86}$ A. A. Franco, M. Guinard, B. Barthe, O. Lemaire. Impact of carbon monoxide on PEFC catalyst carbon support degradation under current-cycled operating conditions. Electrochim. Acta 54 (2009) 5267-5279.

${ }^{87}$ F.A. Uribe, J.A. Valerio, F.H. Garzon, T.A. Zawodzinski. PEMFC reconfigured anodes for enhancing CO tolerance with air bleed. Electrochem. Solid State Lett. 7 (2004) A376-A379.

${ }^{88}$ C. Huang, R. Jiang, M. Elbaccouch, N. Muradov, J.M. Fenton. On-board removal of CO and other impurities in hydrogen for PEM fuel cell applications. J. Power Sources 162 (2006) 563-571.

${ }^{89} \mathrm{Z}$. Shi et al. Transient analysis of hydrogen sulfide contamination on the performance of a PEM fuel cell. J. Electrochem. Soc. 154 (2007) B609-B615. 
${ }^{90}$ E.L. Brosha, T. Rockward, F.A. Uribe, F.H. Garzon. Measurement of H2S Crossover Rates in Polymer Fuel Cell Membranes Using an Ion-Probe Technique. J. Electrochem. Soc. 157 (2010) B180B186. 